S2 Table Development of the His-PVR capture assay (Experiment 3). Fold change of mean RNA copy numbers with His-PVR protein capture (treated) were compared to untreated samples (RNA extracted without capture) and $P$-values calculated by t-test. PCR was performed using $10 \mu \mathrm{L}$ of template RNA in $20 \mu \mathrm{L}$ final reaction volume.

\title{
Conditions tested
}

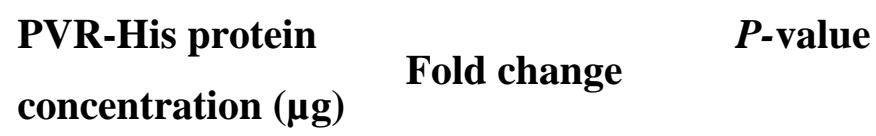

\begin{tabular}{cccc}
\hline Sodium chloride v/v & & & \\
\hline \multirow{2}{*}{ No saline } & 0.1 & 1.9 & $<0.02$ \\
\cline { 2 - 4 } & 1 & 2.2 & $<0.01$ \\
\hline \multirow{2}{*}{$0.9 \%$ saline } & 0.1 & $\mathrm{n} / \mathrm{a}^{*}$ & $\mathrm{n} / \mathrm{a}$ \\
\cline { 2 - 4 } & 1 & 2.7 & $>0.05$ (n.s.) \\
\hline $0.9 \% \mathrm{NaCl}$ vs. no saline & 0.1 & 1.2 & $>0.05$ (n.s.) \\
\hline
\end{tabular}

\#Ni-NTA-agarose was maintained at 10\% v/v, and PEG 6000 7.5\% v/v in 0.01M TE buffer for experiment 3. *n/a: RNA not recovered in experiment (no $\mathrm{C}_{\mathrm{T}}$ values) or PCR was inhibited by high salt content that was not removed during RNA extraction 